\title{
CORRIGENDA
}

\section{Genome-wide association study identifies SESTD1 as a novel risk gene for lithium-responsive bipolar disorder}

\author{
J Song, SE Bergen, A Di Florio, R Karlsson, A Charney, DM Ruderfer, EA Stahl, Members of the International Cohort Collection for \\ Bipolar Disorder (ICCBD), KD Chambert, JL Moran, K Gordon-Smith, L Forty, EK Green, I Jones, L Jones, EM Scolnick, P Sklar, JW Smoller, \\ P Lichtenstein, C Hultman, N Craddock and M Landén
}

Molecular Psychiatry (2017) 22, 1223; doi:10.1038/mp.2016.246; published online 14 February 2017

Correction to: Molecular Psychiatry advance online publication, 27 October 2015; doi:10.1038/mp.2015.165

The list of authors in the HTML version of the article incorrectly included all the members of the International Cohort Collection for Bipolar Disorder. The PDF version correctly lists only the primary authors, as shown above. (The cohort members are listed at the end of the published article.).

In addition, following publication, the authors discovered an error in a subset of the sample affecting the results. A database error led to mismatched phenotypes for the objective lithium-response measures in the Swedish data. This resulted in the total number of lithium responders (objective measurements) in the second wave of Swedish data changing from 159 to 223 and that of nonresponders from 780 to 719 (the correct numbers are underscored in the revised Table 1 shown here). This also changed the total number of subjects entered into the meta-analysis. The numbers of responders and nonresponders were also changed in the first wave of Swedish data (Table 1), but this wave was not used in the original analyses (because the low number of subjects did not allow for an analysis) and thus did not affect the results.

As a consequence of this error, the results of the genetic analyses changed (Table 2, final section): (1) The former top hit, rs 146727601, had a $P$-value of $1.33 \times 10^{-8} \quad(\mathrm{OR}=3.98)$, but changed to $1.22 \times 10^{-9}(\mathrm{OR}=4.12)$ in the revised analyses. (2) The other significant association, rs116323614 in SESTD1, changed from $P=2.74 \times 10^{-8}(\mathrm{OR}=3.14)$ to $1.53 \times 10^{-6}(\mathrm{OR}=2.69)$.

Table 2 shows the corrected meta-analysis comparing lithium responders (objective assessment) with controls.
Table 1. Sample sizes by group and study [the corrected values are underscored]

\begin{tabular}{lcccc}
\hline Phenotype assessment & \multicolumn{2}{c}{ Swedish sample } & UK BDRN & Meta-analysis \\
\cline { 2 - 3 } & Wave 1 & Wave 2 & \\
\hline $\begin{array}{l}\text { Subjective measurement } \\
\text { Responders }\end{array}$ & 149 & 588 & 902 & 1639 \\
$\quad \begin{array}{l}\text { Nonresponders } \\
\text { Controls }\end{array}$ & 45 & 338 & 676 & 1059 \\
& 2215 & 1271 & 5413 & 8899 \\
$\begin{array}{l}\text { Objective measurement } \\
\text { Responders }\end{array}$ & - & $\underline{223}$ & 164 & $\underline{387}$ \\
$\quad \begin{array}{l}\text { Nonresponders } \\
\text { Controls }\end{array}$ & - & $\underline{719}$ & 73 & $\underline{792}$ \\
\hline $\begin{array}{l}\text { Abbreviation: BDRN, Bipolar Disorder Research Network; GWAS, genome- } \\
\text { wide association study; OR, odds ratio. The numbers are subjects with: (1) } \\
\text { available assessments of lithium response according to our definition (for } \\
\text { details, see Supplementary Methods) and (2) passed genotyping quality } \\
\text { control. Too few subjects in Sweden wave 1 had objective measures of } \\
\text { lithium response. Therefore, a GWAS for that sample and measure was not } \\
\text { able to be performed. }\end{array}$ \\
\hline
\end{tabular}

A Supplementary Corrigendum file describing all article corrections in detail, including a revised Figure $1 \mathrm{~b}$, is provided with the corrigendum online.

\begin{tabular}{|c|c|c|c|c|c|c|c|c|c|}
\hline 11 & rs146727601 & $-T / A$ & 0.01 & 4.12 & $1.22 \times 10^{-9}$ & 2 & $112118590-112343856$ & 225 & PTS,PLET1 \\
\hline 19 & rs77866734 & $\mathrm{C} / \mathrm{T}$ & 0.98 & $\underline{0.29}$ & $7.59 \times 10^{-7}$ & 11 & 1633923-1642221 & 8 & TCF3, KIR3DP1, KIR2DL4 \\
\hline 17 & rs142643109 & $T / G$ & 0.98 & $\underline{\overline{0.31}}$ & $4.04 \times 10^{-6}$ & 3 & $60086587-60497572$ & 411 & $\begin{array}{l}\text { TBC1D3P2, MIR4315-2, MIR4315-1, } \\
\text { METTL2A, MED13, EFCAB3 }\end{array}$ \\
\hline
\end{tabular}

